\title{
The cost of ventilator-dependent spinal cord injuries-patients in the hospital and at home
}

\author{
U Bötel, E Gläser, A Niedeggen and R Meindl
}

\author{
Department of Spinal Cord Injuries, 'Bergmannsheil', University Hospital, D-44789 Bochum, Germany
}

\begin{abstract}
The number of ventilator-dependent SCI-patients is increasing steadily but also are the costs of adequate treatment in and outside hospital. Various technical aids for ventilation, mobility, nursing, and individual needs are available for a qualified life in the family, but the costs of these add up to $\$ 116.450$. As phrenic nerve stimulators are very expensive, the cost for permanent ventilation cannot be reduced although diaphragmatic pacemakers have a real significant benefit for the patient's independence and quality of life. As the hospital charge is equal for all paraplegic, tetrapeglic and ventilator-dependent patients including all medical and rehabilitative treatments, drugs and disposable materials, SCI-departments have a marked financial reduction of $\$ 481$ daily compared with the amount of $\$ 1027$ which has to be raised daily for the qualified care at home. This challenge can only be met by help from the community and from insurance companies and it is onlythen possible to provide these severely disabled patients with a good quality of life.
\end{abstract}

Keywords: respiratory insufficiency; phrenic nerve stimulation/mechanical ventilation; home care for severely disabled; tetraplegia; spinal cord injury

\section{Introduction}

Since the possibilities of resuscitation after accidents have improved markedly during the course of the last 15 years, at least in developed and industrialized countries, the number of spinal cord injuries (SCI)patients with long-lasting respiratory insufficiency has increased steadily. The survival and reintegration of these patients has become a great challenge. On the basis of the experiences of Glenn ${ }^{1,2}$ Gerner was the first doctor, in Germany to take care of these severely disabled patients. ${ }^{3,4}$ Meanwhile many SCI-departments have to deal with the challenge due to the increasing numbers. In our department we had to treat and reintegrate 16 patients with ultra-high post-traumatic tetraplegia and permanent respiratory insufficiency since 1989, only a few having complete tetraplegia below $\mathrm{C} 1$ or $\mathrm{C} 2$ immediately after the injury but most developing the respiratory insufficiency within the first $4-8 \mathrm{~h}$ after the accident, sometimes after insufficient treatment following the injury, especially after overdistraction of the spine or secondary dislocation of unstable lesions of $\mathrm{C} 1$ or $\mathrm{C} 2$. Surgical procedures with stabilization alone could not change the neurological outcome but could improve the conditions for mobilization and nursing.

Despite the world-wide experiences with phrenic nerve stimulation ${ }^{1,4,5-7}$ we have had up to now

Correspondence: U Bötel only two patients with diaphragmatic pacemakers as we have found very strict indications for this procedure.

Our philosophy for the treatment of SCI-patients with permanent respiratory insufficiency was mainly: to reduce the time of treatment in the intensive care unit; to achieve early mobility; to improve the quality of life; to reintegrate the patient as soon as possible to his/her family and former social surrounding; to stabilize psychologically.

The motivation difficulties for ventilator-dependent patients have rarely been investigated, ${ }^{8}$ but for psychological reasons there is often social isolation, ${ }^{9}$ which must be overcome. A distinct correlation between effective coping and perceived quality of life in SCI-patients has been reported. ${ }^{10}$ Our aim therefore was mainly the reintegration to the former social environment despite all of the difficulties and the expense. As has been seen in other countries, ${ }^{11}$ we felt that a life-long stay in hospital or a nursing home would not be appropriate for such patients.

To achieve this goal a number of helpful aspects require consideration, especially: technical aids; qualified nursing around the clock; adequate housing; special transportation; and financial support.

The cost of this support is enormous and greatly exceeds the financial possibilities of a family. Society and various insurances have therefore to secure the vital interests of these patients. 
The cost of ventilator-dependent SCI-patients

Due to the very high costs for necessary technical aids for all SCI-patients with ventilatory permanent insufficiency, significant financial help is necessary. Further stay in a nursing home is insufficient for further care, and for reintegration in the family. It is necessary to provide two mobile respirators, $\$ 16.430$ each, and two suction-units, \$2.143 each, to install the necessary security for the patient in case of mechanical defects. Additionally an oxymeter and a carboxymeter are required for permanent registration of the oxygenation; also a chest vibrator to loosen excretions. The total cost for this technical equipment for permanent ventilation will exceed $\$ 44.726$.

There have been several reports on the benefit of phrenic nerve stimulation. ${ }^{2,4,5-7}$ but the costs must take into account the necessity for an additional ventilator. A diaphragmatic pacemaker is a ventilatory machine, which may have a mechanical failure, thus an additional aid is needed. The cost for the phrenic nerve stimulator is very high $(\$ 53.570)$ so that the alternative costs for the ventilatory equipment reaches $\$ 81.866$.

In addition, the cost for mobility is high regarding technically perfect electrical wheelchairs with supports for the ventilator, also for push-chairs. Thus $\$ 25.000$ must be invested.

Compared with these amounts the cost for technical aids for nursing are lower but are nevertheless essential. A patient-lifter is needed as well as an electrically operated bed, and a shower-stretches and also transfer-aids, with a total of approximately $\$ 12.800$

For the personal independence of such SCI-patients we require a well differentiated environmental control (\$28.570), a page-turner for independent reading and a number of smaller aids (eg, mouth-sticks etc), adding up to $\$ 33.940$.

Enormous differences will be noted in the costs between hospitalized patients and those cared for at home, as all daily costs in hospital have to be covered by a daily charge of $\$ 606$ despite the severity of the spinal cord lesion. The cost at present includes everything; medical and surgical treatment, physiotherapy, occupational therapy, nursing, and psychological help etc. for paraplegic, tetraplegic - including ventilator-dependent patients. On the other hand, patients at home have to pay separately. With $\$ 928$ the highest amount is for nursing but there are also costs for physiotherapy, doctor's visits and materials etc exceeding a daily amount of \$1.027. This means that patients at home need beside the technical equipment $\$ 357.386$ per year. Whilst under the current regulations stay in our department only costs $\$ 220.350$ which means a balance of $\$ 118.370$ per year. The desired better qualified life outside the hospital requires the greatest amount of nursing around the clock, but also the other items:

\begin{tabular}{lr} 
Daily cost per year: & \multicolumn{1}{c}{$\$$} \\
nursing & 338.720 \\
disposables & 15.695 \\
medical doctor & 6.160 \\
physiotherapy/OT & 6.160 \\
technical supervision for & \\
ventilator & 1.071 \\
tracheal tubes & 364 \\
ventilator tubes & 216 \\
& \\
Total & 357.386
\end{tabular}

Independent from these costs for technical equipment must be considered:

$\begin{array}{lc}\text { Technical equipment: } & \$ \\ \text { technical aids for ventilation } & 44.726 \\ \text { technical aids for mobility } & 25.000 \\ \text { technical aids for nursing } & 12.786 \\ \text { personal equipment } & 33.940 \\ & \\ \text { Total } & 116.542\end{array}$

This means that after discharge from hospital care a total of $\$ 473.838$ has to be provided for the first year, which is much more than a family could pay without help from the community or from an insurance company.

In comparison to the extremely high cost of ventilator-dependent SCI-patients the cost of nonventilator-dependent patients with a lesion below $\mathrm{C} 4$ are markedly less. These patients need less in the way of financial resources for nursing, even when they require help over $24 \mathrm{~h}$, as they can be managed by less experienced personnel, even, for much of the time, nursing helpers and civil servants. The amount of physiotherapy and occupational therapy will be the same but the medical doctor will only be necessary half of the time. Less in the way of disposables are necessary, as suction tubes and gloves are not needed.

The technical equipment will also be cheaper in some aspects as special additional equipment for the adaption of wheelchairs is not necessary, and technical aids for ventilation are not needed, but the technical aids for nursing and personal equipment for environmental control will be the same.

Nevertheless there are high costs:

$\begin{array}{lc}\text { Daily cost per year: } & \$ \\ \text { nursing } & 99.996 \\ \text { disposables } & 10.600 \\ \text { medical doctor } & 3.080 \\ \text { physiotherapy/OT } & 6.160\end{array}$

Total

Technicals equipment:

technical aids for mobility $\quad 22.334$

technical aids for nursing $\quad 12.786$

personal equipment $\quad 33.940$

Total

69.060 


\section{Conclusions}

Without doubt it is necessary to transfer a ventilatordependent SCI-patient as soon as he is able to breathe ventilator-assisted without additional oxygenation from the intensive care unit to the peripheral SCI-unit for psychological reasons, as we have always noted a marked improvement of motivation and coping after the transfer, even more so after reintegration at home. But the extremely high costs must be covered in comparison to the costs of further hospitalisation under current regulations. It is therefore necessary to change the regulations and daily charges for ventilatordependent SCI-patients according to the actual costs, in order to give the insurance company a stimulus to compensate the financial difference. Undoubtedly, in our experience, the psychological effect of returning home is extraordinary for ventilator-dependent SCIpatients, provided that nursing care with relief for the family, and technical aids can be achieve. With modern medical treatment and immediate intensive care after the accident nowadays the challenge for survival can be met. It is therefore vital to take into account the survival and quality of life, and that means sufficient financial support by the community.

\section{References}

1 Glenn WWL. Diaphragm pacing: present status. Pace 1978; 1: $357-370$.

2 Glenn WWL, Hogan JF, Phelps ML. Ventilatory support of the quadriplegic patient with respiratory paralysis by diaphragm pacing. Surg Clin North Am 1980; 60/5: 1055-1078.

3 Gerner HJ, Kluger P. Ateminsuffizienz bei Querschnittlähmungen In: Schirmer M (ed). Querschnittlähmungen. Springer: BerlinHeidelberg 1986, pp. 490-499.

4 Gerner HJ, Kluger P, Meister B. Experience with use of auxilliary ventilatory muscles and carousel stimulation of the phrenic nerve for ventilation of patients with high tetraplegia. In: Baer GA, Frey $\mathrm{H}$, Talonen PP (eds). Implanted phrenic nerve stimulators for respiratory insufficiency. Acta Univ. Tamperensis B, 1989, 30: $87-100$

5 Baer GA et al. Phrenic nerve stimulation for central ventilatory failure with bipolar and four-pole electrode systems. Pace 1990; 13(8): $1061-1072$.

6 Brûle JF, Lériche B, Normand J, Morel P. Traumatise médullaire haut: évaluation de la fonction diaphragmatique, indication de la ventilation électrophrénique. Agressologie 1993; 34 Spec No 2: $90-92$.

7 McEwen DR. Diaphragmatic pacing. An option for patients with quadriplegic respiratory paralysis. AORN J 1993; 58(3): $547-$ 558.

8 Jordan SA, Wellborn WR, Kovnick J, Saltzstein R. Understanding and treating motivation difficulties in ventilatordependent SCI-patients. Paraplegia 1991; 29(7): 431 - 442.

9 Blake K. The social isolation of young men with quadriplegia. Rehabil-Nurs 1995; 20(1): 17-22.

10 Nieves CC, Charter RA, Aspinall MJ. Relationship between effective coping and perceived quality of life in spinal cord injured patients. Rehabil Nurs 1991; 16(3): 129-132.

11 Kimura K, Ohhata I. The introduction of home mechanical ventilation in Japan. Nippon Kyobu Shikkan Gakkai Zasshi 1992; 30 Supp: $169-174$. 